\title{
POMADA ORGÂNICA NATURAL OU SOLUÇÃO SALINA ISOTÔNICA NO TRATAMENTO DE FERIDAS LIMPAS INDUZIDAS EM RATOS
}

\author{
NATURAL ORGANIC OINTMENT OR ISOTONIC SALINE IN THE TREATMENT OF CLEAN \\ WOUNDS INDUCED IN RATS
}

\author{
Sheila Canevese Rahal ${ }^{1} \quad$ Noeme Sousa Rocha $^{2}$ Érika Paula Blessa $^{3}$ Simone Iwabe $^{4}$ \\ Adalberto José Crocci $^{5}$
}

RESUMO

Foram utilizados 40 ratos Wistar, machos, com peso inicial médio de 225 gramas, separados em dois grupos. Após serem anestesiados com éter, foi induzida uma ferida limpa na região torácica dorsal cranial, mediante a utilização de molde metálico de 2,0 $\times 1,5 \mathrm{~cm}$. No grupo I, foi utilizada pomada contendo óleo de fígado de bacalhau, extrato de confrei, extrato cítrico, óxido de zinco e veículo (Creamex®); no grupo II, a ferida foi apenas limpa com solução salina isotônica. Para a avaliação histológica, foram submetidos à eutanásia cinco animais de cada grupo no $3^{\circ}, 7^{\circ}, 14^{\underline{o}}$ e $21^{\circ}$ dia de pós-operatório. O grupo tratado com a pomada orgânica apresentou padrão cicatricial de qualidade superior em relação ao grupo tratado com salina isotônica, representado por formação de fibras colágenas, neoformação de vasos e reepitelização completa da epiderme.

Palavras-chave: ferida, cicatrização, pomada orgânica, solução fisiológica, ratos.

\section{SUMMARY}

Forty male Wistar rats, with average weight of 225 grams, were divided into two experimental groups. A clean wound was induced in the dorsal thoracic region using a $2.0 x$ $1.5 \mathrm{~cm}$ metallic mould after ether general anesthesia. In the group An ointment containing cod liver oil, comfrey extract, citrus extract, zinc oxide and carrier were used, and in the group II the wound was only cleaned by the use of isotonic saline. Five animals from each group were submitted to euthanasia at 3,7,14 and 21 postoperative days for histological examination. The group using organic ointment showed superior healing pattern when compared to the group using isotonic saline, represented by collagen fiber formation, vessel ingrowth and total reepithelialization of the epidermis.

Key words: wound, healing, organic ointment, isotonic saline, rats.

\section{INTRODUÇÃO}

A transição entre os estádios de inflamação, debridamento e reparo de uma ferida são sutis. Os elementos celulares variam de acordo com o tipo de ferida e guiam o processo de cicatrização (SWAIM \& HENDERSON, 1997). Na ferida limpa o pico da resposta inflamatória pode aparecer em cerca de três a quatro dias (BANKS, 1992). Os neutrófilos são as primeiras células inflamatórias a aparecer mas, na ausência de infecção e restos celulares, diminuem rapidamente em número (SWAIM \& HENDERSON, 1997). Os macrófagos mediam a transição da fase inflamatória para a proliferativa, sendo importantes para o debridamento e recrutamento de fibroblastos (FOWLER, 1993; TIAGO, 1995; WITTE \& BARBUL, 1997).

$\mathrm{Na}$ cicatrização por segunda intenção, o tecido de granulação, formado pela proliferação de fibroblastos e capilares, constitui barreira contra infecção, superfície para a migração do epitélio e

\footnotetext{
${ }^{1}$ Médico Veterinário, Professor Assistente, Doutor, Departamento de Cirurgia e Anestesiologia Veterinária, Faculdade de Medicina Veterinária e Zootecnia (FMVZ), Universidade Estadual Paulista (UNESP), Campus de Botucatu, 18618-000, Rubião Júnior s/n, Botucatu, SP. Email:sheilacr@fmvz.unesp.br. Autor para correspondência.

${ }^{2}$ Médico Veterinário, Professor Assistente, Doutor, Departamento de Clínica Veterinária (Setor de Patologia) FMVZ/UNESP, Botucatu.

${ }^{3}$ Aluno de iniciação à pesquisa CNPq/PIBIC - FMVZ/UNESP, Botucatu.

${ }^{4}$ Médico Veterinário, Autônomo.

${ }^{5}$ Professor Assistente, Doutor, Departamento de Bioestatística, Instituto de Biociências/UNESP, Botucatu.
} Recebido para publicação em 02.10.00. Aprovado em 07.03.01 
tem papel na contração da ferida (SWAIM \& HENDERSON, 1997). Uma das principais funções dos fibroblastos é a síntese de colágeno (TIAGO, 1995), sendo que a resistência da cicatriz é determinada pela velocidade, quantidade e qualidade da deposição do mesmo (WITTE \& BARBUL, 1997).

A melhor conduta para favorecer a cicatrização de uma ferida, segundo JOHNSTON (1990), é a remoção de fatores inibitórios, bem como a correção de deficiências nutricionais. No entanto, é importante lembrar que uma série de agentes tópicos, tais como anti-sépticos, antibióticos e curativos exercem algum efeito no local da ferida, sendo em alguns casos tão adversos que prejudicam a cicatrização. Anti-sépticos e determinadas substâncias químicas destroem bactérias, mas também lesam as células corporais; por outro lado, soluções salinas isotônicas, Ringer ou Ringer lactato não têm atividade sobre bactérias, mas são fisiológicas e não causam dano aos tecidos (JOHNSTON, 1981; SWAIM \& HENDERSON, 1997). De acordo com TIAGO (1995), uma vez que a solução salina isotônica não irrita e nem retarda a cicatrização pode ser utilizada em todas as feridas limpas. Com relação à epitelização, as bandagens parecem ser mais benéficas à migração do que a mitose; entretanto, coberturas aderentes são lesivas à epitelização, porque permitem o crescimento de células epiteliais nos interstícios do material (SWAIM, 1980).

Atualmente está havendo um crescente interesse em produtos medicinais naturais. A Quinabra (Química Natural Brasileira Ltda.) desenvolveu uma pomada anti-séptica e cicatrizante (Creamex $\left.{ }^{\circledR}\right)$ de origem orgânica natural (fitoterápica), que aproveita de forma sinergética a associação biológica do CITREX-líquido (extrato cítrico), considerado bacteriostático e fungistático, com o extrato de confrei, considerado cicatrizante e regenerador da pele. Além desses componentes, a pomada tem como coadjuvantes o óleo de fígado de bacalhau, o óxido de zinco e um veículo inerte (QUINABRA, 1998).

O confrei (Symphytum officinale) é uma planta com propriedades anti-séptica, bactericida e fungicida e, em menor grau, antiinflamatória, antipruriginosa, cicatrizante e emoliente (TIAGO, 1995). O suco extraído de suas raízes pode ser utilizado, externamente, como detergente e calmante de feridas, tumores, inchaços e contusões (MORGAN, 1979).

O óxido de zinco é componente de muitas pomadas, pós, pastas e loções dermatológicas, tendo basicamente quatro propriedades no tratamento de lesões cutâneas: proteção, leve adstringência, fraco poder anti-séptico e ausência de toxicidade (BOOTH, 1977). SWAIM (1980) afirmou que os resultados dos efeitos do sulfato de zinco em feridas são variáveis e quando foi usado topicamente para tratar ulcerações crônicas da perna não melhorou a cicatrização.

KIETZMANN (1996) comparou, no tratamento de feridas em ratos, a pomada de óxido de zinco com a de óleo de fígado de bacalhau, observando um aumento na taxa de cicatrização de ambos os grupos em relação ao controle. Posteriormente, ao combinar o óxido de zinco com o óleo de fígado de bacalhau verificou uma melhor reação cicatricial em relação aos grupos anteriormente testados. Segundo o autor, o óxido de zinco e o óleo de fígado de bacalhau atuam em sinergismo. O óleo de fígado de bacalhau inibe o aumento da concentração epidermal de eicosanóides, que são fatores essenciais na reação inflamatória, ao passo que óxido de zinco induz a um aumento da reação proliferativa.

A pomada Creamex ${ }^{\circledR}$ foi aplicada em humanos, com ótimos resultados e sem nenhuma manifestação de alergia. Foi utilizada no tratamento de feridas e incisões de pele, queimaduras, assaduras, abscessos, furúnculos, infecções externas dos órgãos genitais e como coadjuvante no tratamento de dermatoses produzidas por fungo (QUINABRA, 1998).

Foram realizados estudos clínicos, pela Clínica Dermatológica Arbache (São José dos Campos), comprovando a ausência de danos fotossensíveis do princípio ativo (DF 100 à 0,5\%). Na Irmandade da Santa Casa de Misericórdia de São José dos Campos, foi utilizada em pacientes com queimaduras de primeiro, segundo e até terceiro graus e áreas que necessitavam de enxerto. Os resultados foram satisfatórios, favorecendo a cicatrização e evitando a contaminação. Por não ocorrer a aderência da pomada e bandagem na região da lesão, foi possível evitar o processo doloroso da troca do curativo (QUINABRA, 1998).

Considerando que a cicatrização de feridas por segunda intenção é um processo complexo e os insucessos relacionados ao tratamento continuam sendo um problema clínico importante, o trabalho teve por objetivo estudar histologicamente a resposta cicatricial de feridas limpas tratadas com solução fisiológica $0,9 \%$ ou com a pomada Creamex, um produto orgânico natural.

\section{MATERIAL E MÉTODOS}

Foram utilizados 40 ratos Wistar, machos, com peso inicial médio de 225 gramas, alojados em 
gaiolas individuais com água e ração ad libitum, separados aleatória e equiitativamente em dois grupos.

Após anestesia inalatória com éter, foi feita a tricotomia da região torácica e a preparação da mesma para procedimento asséptico. Foi demarcado na região torácica dorsal cranial, mediante a utilização de molde metálico, um retângulo de $2,0 \mathrm{x}$ $1,5 \mathrm{~cm}$. A pele demarcada foi incisada e, em seguida, foi excisado um segmento retangular constituído de pele, tecido subcutâneo e músculo panículo carnoso.

As feridas foram tratadas e avaliadas diariamente, sendo protegidas com bandagem composta de compressa de gaze (primeira camada) e atadura de crepe (segunda camada). No grupo I, foi utilizada uma pomada ${ }^{a}$ contendo óleo de fígado de bacalhau, extrato de confrei, extrato cítrico, óxido de zinco e veículo; no grupo II, a ferida foi apenas limpa com solução fisiológica $0,9 \%$ b . Durante a troca das bandagens, os animais foram anestesiados com éter e as feridas irrigadas com solução fisiológica para minimizar o trauma na remoção da gaze.

Para a realização dos exames histológicos, cinco animais dos grupos I e II, foram submetidos à eutanásia aos 3, 7, 14 e 21 dias de pós-operatório. As lesões foram colhidas, junto com a pele circundante, e fixadas em formalina tamponada a $10 \%$. Após a fixação, o material foi processado e corado para Hematoxilina-Eosina e Tricrômico de Masson. A leitura foi feita em microscopia óptica, visando observar o processo inflamatório e cicatricial.

Para cada variável avaliada no experimento (neovasos, fibroblastos, neutrófilos, macrófagos, hemácias, fibras colágenas, fibrina e basófilos), a comparação entre os dias de avaliação para cada grupo foi realizada pelo teste não paramétrico de Kruskal-Wallis e a comparação entre os grupos em cada um dos dias de avaliação pelo teste não paramétrico de Mann-Withney (SIEGEL, 1975). As comparações múltiplas entre dias de avaliação, dois a dois, foram realizadas ao nível de $5 \%$ de significância. A quantificação de cada variável observada seguiu o esquema: $0=$ ausente, mínimo $=1(+)$, moderado $=2(++)$, intenso $=3(+++)$.

\section{RESULTADOS}

Foi observado que, inicialmente, a pomada não tinha poder de adesão à ferida, sendo necessária a utilização de bandagens; com o tratamento, ela impregnava a superfície da lesão, especialmente partir do $5^{\mathrm{o}}$ dia. Durante a troca das bandagens, verificou-se que, no grupo I, não havia aderência da gaze à ferida, ao passo que no grupo II, a aderência foi significativa. Não foram detectados sinais de infecção em nenhum dos grupos.
A análise histológica das feridas dos animais dos grupos I e II, sacrificados no $3^{\circ}$ dia de pósoperatório, mostrou intenso infiltrado inflamatório (neutrófilos, macrófagos, basófilos) associado à intensa hemorragia e presença de fibrina. No $7^{\circ}$ dia, a situação foi aparentemente similar havendo, no entanto, a presença de fibroblastos e diminuição do número de neutrófilos no grupo I em relação ao II. No $14^{\circ}$ dia, as diferenças já foram observadas, com a presença de neovasos, fibroblastos e fibras colágenas em maior número no grupo I, além da ausência de fibrina e hemácias. No $21^{\mathrm{o}}$ dia, o grupo I, com a pomada orgânica, apresentou um padrão cicatricial bem definido, representado por fibras colágenas, neoformação de vasos e fibroblastos e epitelização completa da epiderme, o que não foi evidenciado no grupo II (Figura 1). Não foram verificadas diferenças estatisticamente significantes entre os grupos com relação aos macrófagos e basófilos, mas houve uma diminuição progressiva dos basófilos entre os momentos, ao passo que, nos macrófagos, isso foi verificado do $14^{\circ}$ para o $21^{\circ}$ dia. As diferenças foram observadas tanto pela Hematoxilina-eosina como no Tricrômico de Masson.

As medianas, de cinco repetições, correspondentes a neovasos, fibroblastos, neutrófilos, macrófagos, hemácias, fibras colágenas, fibrina e basófilos dos animais dos grupos I e II, durante os momentos de observação, encontram-se na tabela 1 .

\section{DISCUSSÃO}

O baixo poder de aderência da pomada à ferida, especialmente nos primeiros dias de tratamento, pode ser um fator limitante ao emprego

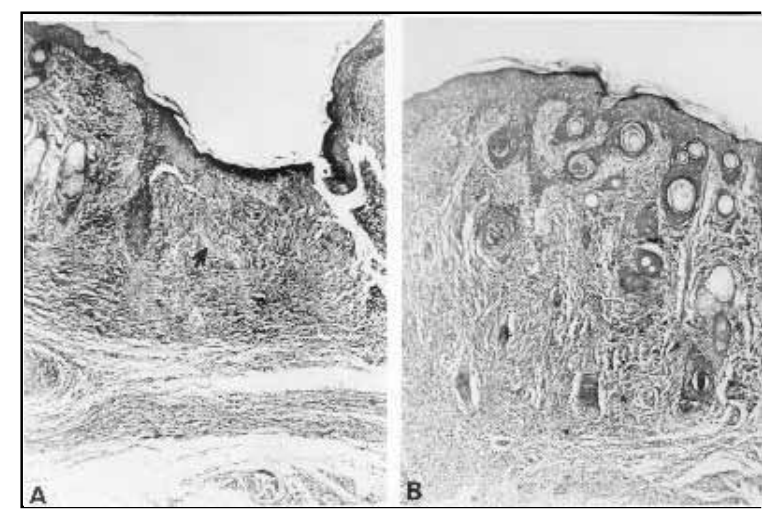

Figura 1 - Corte histológico das feridas de ratos do grupo II (a) e I (b) aos 21 dias. Na ferida do animal tratado com solução fisiológica $0,9 \%$ (a), há uma organização das fibras colágenas (seta), ao passo que na do rato tratado com pomada orgânica (b) há epitelização da epiderme e regeneração da derme superficial e profunda. (Tricrômico de Masson - 20X). 
Tabela 1 - Medianas, de 5 repetições, de neovasos, fibroblastos, neutrófilos, macrófagos, hemácias, fibras colágenas, fibrina e basófilos, segundo grupos (I - pomada orgânica, II - solução fisiológica $0,9 \%$ ) e momentos de avaliação.

\begin{tabular}{lcllll}
\hline Momentos & & & & & \\
Variável & Grupos & $3^{0}$ dia & $7^{\circ}$ dia & $14^{\circ}$ dia & $21^{\circ}$ dia \\
Neovasos & I & $0 \mathrm{aA} *$ & $0 \mathrm{aA}$ & $3 \mathrm{aB}$ & $2 \mathrm{aB}$ \\
& II & $0 \mathrm{aA}$ & $0 \mathrm{aA}$ & $1 \mathrm{bB}$ & $1 \mathrm{bB}$ \\
Fibroblastos & I & $0 \mathrm{aA} *$ & $1 \mathrm{aB}$ & $3 \mathrm{aC}$ & $3 \mathrm{aC}$ \\
& II & $0 \mathrm{aA}$ & $0 \mathrm{bA}$ & $2 \mathrm{bB}$ & $2 \mathrm{bB}$ \\
Neutrófilos & I & $3 \mathrm{aA} *$ & $2 \mathrm{aA}$ & $1 \mathrm{aB}$ & $0 \mathrm{aC}$ \\
& II & $3 \mathrm{aA}$ & $3 \mathrm{bA}$ & $2 \mathrm{bA}$ & $1 \mathrm{bB}$ \\
Macrófagos & I & $2 \mathrm{aA} *$ & $3 \mathrm{aA}$ & $2 \mathrm{aA}$ & $1 \mathrm{aB}$ \\
& II & $2 \mathrm{aA}$ & $2 \mathrm{aA}$ & $2 \mathrm{aA}$ & $0 \mathrm{aB}$ \\
Hemácias & I & $2 \mathrm{aA} *$ & $1 \mathrm{aB}$ & $0 \mathrm{aC}$ & $0 \mathrm{aC}$ \\
Fibras & II & $2 \mathrm{aA}$ & $1 \mathrm{aA}$ & $1 \mathrm{bA}$ & $2 \mathrm{bA}$ \\
colágenas & I & $0 \mathrm{aA} *$ & $0 \mathrm{aA}$ & $2 \mathrm{aB}$ & $3 \mathrm{aC}$ \\
Fibrina & II & $0 \mathrm{aA}$ & $0 \mathrm{aA}$ & $1 \mathrm{bB}$ & $1 \mathrm{bB}$ \\
& I & $3 \mathrm{aA} *$ & $2 \mathrm{aA}$ & $0 \mathrm{aB}$ & $0 \mathrm{aB}$ \\
Basófilos & II & $3 \mathrm{aA}$ & $2 \mathrm{aA}$ & $2 \mathrm{bB}$ & $1 \mathrm{bC}$ \\
& I & $3 \mathrm{aA} *$ & $2 \mathrm{aB}$ & $1 \mathrm{aC}$ & $0 \mathrm{aD}$ \\
& II & $3 \mathrm{aA}$ & $2 \mathrm{aB}$ & $0 \mathrm{aC}$ & $1 \mathrm{aC}$ \\
\hline
\end{tabular}

* letras minúsculas: comparam grupos em cada momento para cada variável avaliada.

letras maiúsculas: comparam momentos em cada grupo para cada variável avaliada.

Obs: letras diferentes indicam diferença significativa $(\mathrm{P}<0,05)$

da mesma em situações em que a bandagem não pode ser aplicada. Embora haja citações do efeito antiinfeccioso da pomada (QUINABRA, 1998), atribuídos especialmente ao extrato cítrico e confrei, o mesmo não pode ser comprovado, visto ser o rato um animal bastante resistente à infecção e não ter havido sinais da mesma em ambos os grupos.

Histologicamente, tanto no terceiro como no sétimo dia de pós-operatório, verificou-se um processo predominantemente inflamatório, assemelhando-se ao tempo referido por BANKS (1992), como pico da resposta inflamatória de uma ferida limpa. Embora não tenha ocorrido diferença estatística entre os grupos com relação ao número de macrófagos, principal célula fagocitária (FOWLER, 1993; TIAGO, 1995; WITTE \& BARBUL, 1997), a diminuição do número de neutrófilos do grupo tratado com a pomada orgânica em relação ao grupo tratado com solução isotônica a partir do $7^{\circ}$ dia de pós-operatório pode estar associada à ação antiinflamatória do confrei (TIAGO, 1995) e óleo de fígado de bacalhau (KIETZMAN, 1996).

Na pomada Creamex ${ }^{\circledR}$, há diversos componentes, tais como confrei, óxido de zinco e óleo de fígado de bacalhau, que foram considerados por outros estudos (BOOTH, 1977; MORGAN, 1979; TIAGO, 1995; KIETZMAN, 1996) como benéficos à cicatrização de feridas. Os achados histológicos verificados nos animais tratados com a pomada orgânica no $14^{\circ}$ e $21^{\circ}$ dias de pós-operatório, tais como maior número de fibras colágenas, neovascularização e proliferação de fibroblastos, bem como epitelização completa da epiderme, indicam um efeito favorável da pomada no processo de reparo, uma vez que são elementos celulares fundamentais nesta fase da cicatrização por segunda intenção (TIAGO, 1995; SWAIM \& HENDERSON, 1997; WITTE \& BARBUL, 1997).

Ressalta-se que a epitelização atrasada do grupo II pode estar relacionada com o tipo de curativo e não à solução salina, que é isotônica e praticamente não lesiva aos tecidos (JOHNSTON, 1981; TIAGO, 1995; SWAIM \& HENDERSON, 1997). Uma vez que a gaze adere à ferida, mesmo usando irrigação durante a sua remoção, pode haver lesão das células epiteliais (SWAIM, 1980). Como a pomada orgânica promoveu uma cobertura não aderente, houve maior proteção no grupo I. Este efeito também foi observado em pacientes humanos sofrendo de queimaduras, aliado a redução da dor na troca dos curativos (QUINABRA, 1998), que não pôde ser avaliado no experimento, já que os curativos eram trocados com os animais sob anestesia.

\section{CONCLUSÃO}

Foi possível concluir que a pomada orgânica Creamex permite uma cicatrização de qualidade superior em relação ao tratamento com solução salina isotônica, tendo como vantagem a não aderência da bandagem à lesão.

\section{FONTES DE AQUISIÇÃO}

a - CREAMEX® - Quinabra - Rua Sete Lagos, 20 - Caixa Postal 575 - São José dos Campos, SP.

b - Solução fisiológica 0,9\% - Halex e Istar Ltda., Br-153 km3 Goiânia, GO.

\section{REFERÊNCIAS BIBLIOGRÁFICAS}

BANKS, W.J. Histologia veterinária aplicada. 2.ed. São Paulo : Manole, 1992. Cap.20: Sistema tegumentar: p.391-424.

BOOTH, N.H. Medicamentos tópicos. In: JONES, L.M., BOOTH, N.H., McDONALD, L.E. Farmacologia e terapêutica em veterinária. 4.ed. Rio de Janeiro : Guanabara Koogan, 1977. Cap.42, p.594-605.

FOWLER, D. Principles of wound healing. In: HARARI, J. Surgical complications and wound healing in the small animal practice. Philadelphia : Saunders. 1993. Cap.1, p.132 
JOHNSTON, D.E. Skin and subcutaneous tissue. In: BOJRAB, M.J. Pathophysiology in small animal surgery. Philadelphia : Lea \& Febiger, 1981. Cap.43, p.405-415.

JOHNSTON, D.E. Wound healing in skin. The Veterinary Clinics of North America : Small Animal Practice, v.20, n.1, p.1-25, 1990.

KIETZMANN, M. Improvement and retardation of wound healing: effects of pharmacology agents in laboratory animal studies. In: SEMINARS IN DERMATOLOGY ADVANCES IN WOUND HEALING, 1996, Hatfield, England. Anais... Hatfield : Royal Veterinary College, 1996, V.1. 41p. p.39-41

MORGAN, R. Enciclopedia das ervas e plantas medicinais. São Paulo : Hemus, 1979. 555p.

QUINABRA - Química Natural Brasileira Ltda. Creamex. São José dos Campos, 1998. 25p. (Informativo Técnico).
SIEGEL, S. Estatística não paramétrica (para ciências do comportamento). São Paulo : McGraw-Hill, 1975. 320p.

SWAIM, S.F. Surgery of traumatized skin: management and reconstruction. Philadelphia : Saunders, 1980. p.70-115.

SWAIM, S.F., HENDERSON Jr., R.A. Small animal wound management. 2.ed. Baltimore : Williams \& Wilkins, 1997. Cap.3: Wound dressing materials and topical medications: p. $53-85$.

TIAGO, F. Feridas. Etiologia e tratamento. 2ed. Ribeirão Preto : FAEPA, 1995. 161p.

WITTE, M.B., BARBUL, A. Princípios gerais da cicatrização das feridas. In: BARBUL, A. Clínicas Cirúrgicas da América do Norte. Rio de Janeiro : Interlivros, 1997. V.3, p.509-527.

Ciência Rural, v. 31, n. 6, 2001. 